\title{
Liaison between obesity and stress along with their management and control
}

\begin{abstract}
Obesity is thought to be caused by stress and tension as it may influence eating habits behaviors in humans. It is direly needed to check on biological markers which cause stress and to develop some strategies to understand physiological mechanism which affects eating habits. Obesity is the big challenge now-a-days due to day by day increasing stress and change in eating habits i.e. too much rely on fast food. This review focuses on relation between obesity and stress, causes of stress and control of both obesity and stress by various essential ways. Obesity and in turn stress can be controlled by using healthy diet, by taking exercise and use of pure water and by changing life style.
\end{abstract}

Volume 7 Issue 4 - 2017

\author{
Naseem Zahra \\ Food and Biotechnology Research Centre, Pakistan
}

Correspondence: Naseem Zahra, Food and Biotechnology Research Centre, PCSIR Laboratories Complex, Ferozepur Road, Lahore-54600, Pakistan,

Email naseem.zahra198।@gmail.com

Received: October 26, 2017 | Published: November 06, 2017

Keywords: obesity, stress, management, control

\section{Introduction}

\section{Obesity and stress relation}

Obesity is considered as a health disease which may lead to various so many diseases like hypertension, diabetes mellitus, heart diseases and hyperlipidemia. ${ }^{1-4}$ WHO has set criteria for overweight and obesity where overweight is considered when BMI (body mass index) is $25 \mathrm{~kg} / \mathrm{m}^{2}$ or more but less than $30 \mathrm{~kg} /$ $\mathrm{m}^{2}$ and when BMI is more than $30 \mathrm{~kg} / \mathrm{m}^{2}$ it is obesity. There are around 1.5 billion adults who are suffering from obesity which is affecting health badly in both developed and under developed countries. ${ }^{5,6}$ It is very important to tackle obesity with weight management techniques.?

Human behavior is affected by many factors but it is thought that it may vary greatly due to stress. Stress may change food intake timings and ways and it may affect eating behaviors in two ways as over eating or under eating. ${ }^{8}$ Sugar and fat are high energy diets and may severe stress mainly. Obesity may develop in stress environment due to over eating habits. In one study it was revealed that women are more affected to stress-induced eating habits as compared to men while men may take more alcohol in stress environment. ${ }^{9} 10$ There are so many reasons which may cause weight gain. Firstly, it is seen that in stress many people eat more. Stress eating is a kind of emotional eating, which increases calories and when done frequently and repeatedly enough may cause a remarked increase in weight. It is observed that usually people in stress people crave high sugar and fatty foods. Secondly, a hormone named cortisol is produced in stress in large quantity which promotes body fat especially around stomach. In stress body respond to chronic stress by releasing cortisol by messenger hormone ACTH and this process in known as HPA axis (Figure 1). The adrenal cortisol hormone released during stress is eventually accountable for weight gain as it endorses insulin confrontation and increases blood sugar levels which in turn cause heart diseases. ${ }^{11-15}$ Thirdly, during stress someone take less sleep which causes rise in hormone named ghrelin. Ghrelin is considered as primary hunger hormone which causes someone to sense hungry even when there is no need to eat something.

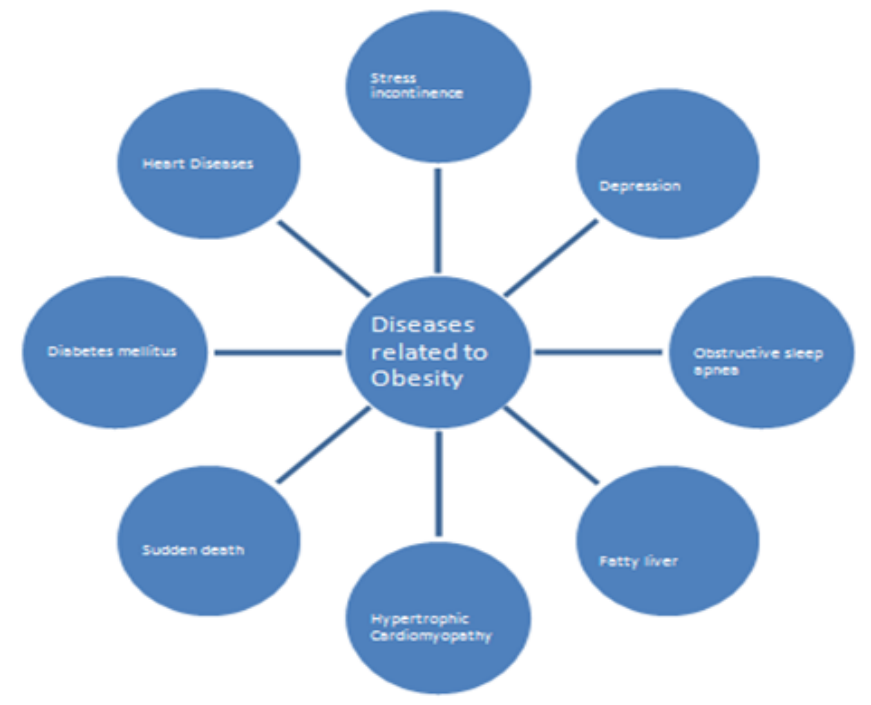

Figure I Diseases related to obesity.

\section{Causes of stress}

Different transitions happen in personal lives which may cause stress. There are so many personal issues which may contribute to stress i.e. tensions of work at workplace, domestic issues like death of loved ones, separation and financial constraints. Additionally poor working environment may enhance stress like noisy, chilly, rushy and high temperatures at workplaces. ${ }^{16}$ Heavy workloads and stickiness to one environment may lead to stress which may change dietary habits and hence obesity may results. Conversely, everything that puts high demands on humans can be stressful and badly affect health. Long term stress can lead to so many diseases like high blood pressure, diabetes, depression, mental disorders and among which obesity is one serious issue.

\section{Obesity and stress management}

By using fruits and vegetables in diet: Meal having both fruits and vegetables contain soluble and insoluble fibers. Insoluble fibers 
include cellulose, hemicelluloses and lignin while soluble fibers include gum, pectin and mucilages mostly found in skin of fruits and vegetables. ${ }^{17}$ It was stated in one research that. ${ }^{18} 1.9 \mathrm{~kg}$ weight loss in 3-4months i.e. $10 \%$ decrease in energy density resulted by consuming fiber of $14 \mathrm{~g}$ /day. By taking into consideration the past findings it can be said that more consumption of fruits and vegetables in diet would reduce energy density and hence obesity. In a study on 60,000 Australians of 45 years and more consuming vegetables in their diets were found mentally active and were free from stress. Women consuming 3-4 servings of vegetables daily reduced stress risk up to $18 \%{ }^{19}$

By exercise: Regular exercise is the most important and effective therapy for both obesity control and stress loss. The synergistic relationship between diet and exercise is appeared to be most easiest way to control obesity and hence various diseases which obesity itself causes. Exercise can change behaviors and its positive effects change eating habits and hence control obesity. ${ }^{20}$ It is very necessary to take different exercises like yoga regularly. It will definitely help to reduce stress in life.

By using water: Water intake increases volume and thereby reduces energy density. Fruits and vegetables have high water and fiber contents and are low in calories and energy density. Water is natural tonic to reduce weight and hence stress out. ${ }^{21}$ Water removes toxins from body and hence reduces stress in body which smoothes nerves. So a generous intake of water daily can reduce obesity in miracle way (Figure 2).

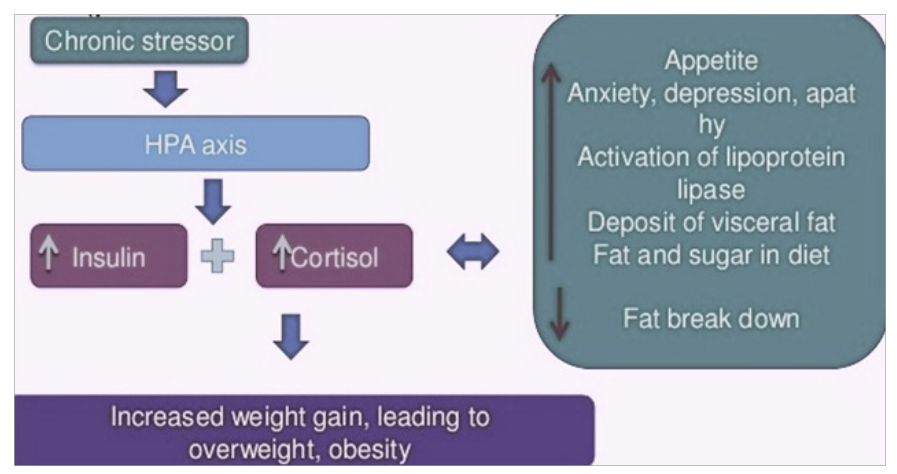

Figure 2 Responses of body against stress to gain obesity.

By changing life style: Balanced healthy life style may greatly affect obesity control. It would be better to avoid stress, boredom, depression and frustration as these can be triggers to detrimental eating behaviors. It is better to involved in enjoyable activities such as socializing with friends and family and involvement in different types of sports which may help in achieving a healthy lifestyle. It is pleasurable to get enrolled in relaxation programs in order to relieve stress. ${ }^{22}$

\section{Conclusion}

It is concluded that there exist a relationship between obesity and stress. In stress and depression eating habits may change and hence overeating may lead to chronic disease of obesity. Obesity and Overweight are dangerous conditions which may contribute to so many chronic diseases like diabetes and heart diseases. Therefore, it is tremendously imperative to treat obesity uncompromisingly. Use of fruits and vegetables, daily exercises, use of munificent amount of water, healthy lifestyle adaption may help in obesity control and hence release stress.

\section{Acknowledgements}

None.

\section{Conflict of interest}

The author declares no conflict of interest.

\section{References}

1. Bray GA. Risks of obesity. Endocrinol Metab Clin North Am. 2003;32(4):787-804

2. Rashid MN, Ruentes F, Touchon RC, et al. Obesity and the risk for cardiovascular disease. Prev Cardiol. 2003;6(1):42-47.

3. Sowers JR. Obesity as cardiovascular risk factors. Am J Med. 2003;115(Suppl 8A):37S-41S.

4. World Health Organization. Obesity: preventing and managing the global epidemic. Part I. The problem of overweight and obesity. WHO Technical Report Series No. 894. Switzerland: WHO; 2000. p. 5-15.

5. Nguyen T, Lau DC. The obesity epidemic and its impact on hypertension. Can J Cardiol. 2012;28(3):326-333.

6. Ginter E, Simko V. Type 2 diabetes mellitus, pandemic in $21^{\text {st }}$ century. Advances in Experimental Medicine and Biology. 2012;771:42-50.

7. Magnusson RS. Rethinking global health challenges: towards a 'global compact' for reducing the burden of chronic disease. Public Health. 2009;123(3):265-274.

8. Torres SJ, Nowson CA. Relationship between stress, eating behavior, and obesity. Nutrition. 2007;23(11):887-894.

9. Greeno C, Wing RR. Stress-induced eating. Psychol Bull. 1994;115(3):444-464.

10. Vasse RM, Nijhuis FJN, Kok G. Association between work stress, alcohol consumption and sickness absence. Addiction. 1998;93(2):231-241.

11. Parker M, Ettinger RH. Understanding Psychology. 2nd ed. USA: Horizon textbook Publishing; 2007.

12. Winick C, Rothacker DQ, Norman RL. Four worksite weight loss programs with high-stress occupations using a meal replacement product. Occup Med. 2002;52(1):25-30.

13. Kouvonen A, Kivimaki M, Cox SJ, et al. Relationship between work stress and body mass index among 45, 810 female and male employees. Psychosom Med. 2005;67(4):577-583.

14. Morse T, Dussetschleger J, Warren N, et al. Talking about health: correction employees' assessments of obstacles to healthy living. $J$ Occup Environ Med. 2011;53(9):1037-1045.

15. Karasek R, Baker D, Marxer F, et al. Job decision latitude, job demands, and cardiovascular disease: a prospective study of Swedish men. Am J Public Health. 1981;71(7):694-705.

16. Karasek RA, Theorell T. Healthy work: Stress, productivity and the reconstruction of working life. USA: Basic Books; 1990.

17. Howarth NC, Saltzman E, Roberts SB. Dietary fiber and weight regulation. Nutr Rev. 2001;59(5):129-139.

18. Tohill BC. Dietary Intake of Fruit and Vegetables and Management of Body Weight. Switzerland: Background paper for Joint FAO/WHO Workshop on Fruit and Vegetables for Health; 2004. p. 1-3.

19. Giles S. Want to beat stress? Fresh fruit and vegetables 'can SLASH anxiety levels'. UK: Daily Express; 2017.

20. NNSC, National Nutrition Surveillance Centre. The Interrelationship between Obesity, Physical Activity, Nutrition and other Determinates. 2009. 3 p. 
21. Rolls BJ, Bell EA, Thorwart ML. Water incorporated into a food but not served with a food decreases energy intake in lean women. Am J Clin Nutr. 1999;70(4):448-455
22. Kumar P, Clark M. Clinical Medicine. 5th ed. USA: WB Saunders Company; 2002. 